\title{
Use of nursing technologies for safe perioperative pediatric care
}

How to cite this article: Ferraz SCS, Rocha PK, Tomazoni A, Waterkemper R, Schoeller SD, Echevarría-Guanilo MEC. Use of nursing technologies for safe perioperative pediatric care Rev Gaúcha Enferm. 2020;41:e20190251. doi: https://doi.org/10.1590/19831447.2020.2019025
` Hospital Unimed Litoral. Balneário Camboriú, Santa Catarina, Brasil.

b Universidade Federal de Santa Catarina (UFSC) Departamento de Enfermagem. Florianópolis, Santa Catarina, Brasil.

Universidade Federal de Ciências da Saúde de Porto Alegre (UFCSPA). Porto Alegre, Rio Grande do Sul, Brasil.

\section{Sheila Cristina da Silva Ferraz Patrícia Kuerten Rochab Andreia Tomazoni ${ }^{b}$ Roberta Waterkemperc Soraia Dornelles Schoeller ${ }^{b}$ Maria Elena Echevarría-Guanilob}

\begin{abstract}
Objective: To understand the nursing team's perception about the use of technology for safe perioperative pediatric care, through photographs.

Method: A qualitative study using the theoretical framework of Nietsche Specific Nursing Technology, with a total of 18 perioperative nursing professionals from a general hospital in southern Brazil. Data collection occurred from June to August 2018, from a semistructured interview and photograph production. They were analyzed through the Thematic Content Analysis. Approved by the Research Ethics Committee of the Federal University of Santa Catarina.

Results: The Nursing Technologies category used for the safety of the pediatric patient in the perioperative period, with 250 photographs illustrating facts, situations and artifacts considered nursing technologies used in safe care.

Conclusions: In the team's perception, patient safety involves the use of technologies integrated to perioperative care and structural, physical and input aspects.

Keywords: Patient safety. Pediatrics. Perioperative care. Nursing. Technology.
\end{abstract}

\section{RESUMO}

Objetivo: Compreender a percepção da equipe de enfermagem quanto ao uso da tecnologia para uma assistência segura no perioperatório pediátrico, por meio da imagem.

Método: Pesquisa qualitativa, utilizou o referencial teórico a Tecnologia Específica de Enfermagem de Nietsche, com 18 profissionais de enfermagem do perioperatório de um hospital geral da região sul do Brasil. A coleta de dados ocorreu de junho a agosto de 2018 a partir de entrevista semiestruturada e a produção de imagens. Analisados por meio da Análise Temática de Conteúdo. Aprovado pelo Comitê de Ética da Universidade Federal de Santa Catarina.

Resultados: A categoria Tecnologias de Enfermagem utilizadas para a segurança do paciente pediátrico no perioperatório, com 250 fotografias ilustrando fatos, situações e artefatos considerados tecnologias de enfermagem usadas na assistência segura.

Conclusões: Na percepção da equipe, a segurança do paciente envolve uso de tecnologias integradas à assistência perioperatória e a aspectos estruturais, físicos e de insumo.

Palavras-chave: Segurança do paciente. Pediatria. Assistência perioperatória. Enfermagem. Tecnologia.

\section{RESUMEN}

Objetivo: Entender la percepción del equipo de Enfermería sobre el uso de la tecnología para una assistência segura en el perioperatory, por medio de la imagen.

Método: Investigación cualitativa, utilizó la referencia teórica a la Tecnología de Enfermería Específica de Nietsche, con 18 profesionales de enfermería perioperatoria de un hospital general de la región sur de Brasil. La recopilación de datos se llevó a cabo de junio a agosto de 2018, a partir de una entrevista semiestructurada y la producción de imágenes. Analizado a través del Análisis de Contenido Temático. Aprobado por el Comité de Ética de la Universidad Federal de Santa Catarina.

Resultados: La categoría Tecnologías de enfermería utilizadas para la seguridad del paciente pediátrico en el período perioperatory, con 250 fotografías que ilustran hechos, situaciones y artefactos considerados tecnologías de enfermería utilizadas en la atención segura.

Conclusiones: Según la percepción del equipo, la seguridad del paciente implica el uso de tecnologías integradas en la atención perioperatoria y aspectos estructurales, físicos y de insumos.

Palabras clave: Seguridad del paciente. Pediatría. Atención perioperativa. Enfermería. Tecnología 


\section{口INTRODUCTION}

Patient safety represents quality in care and must be in all these healthcare areas. Based on the principles of the World Health Organization (WHO), that safety is the absence of preventable harm to the patient, during care process, and the reduction of damage or injuries risks, associated with health care, within a minimum acceptance ${ }^{(1)}$. Nursing seeks to care for the pediatric patient throughout the perioperative period, from the pre-operative to the trans-operative and post-anesthetic recovery room ${ }^{(1-2)}$.

However, through the recommendations of best practices proposed by health organizations on the subject, the rates of adverse events are high and underreported ${ }^{(3)}$, and these rates in pediatric hospitals can reach $19.1 \%$ per patient/day ${ }^{(4)}$. According to the latest WHO report, Patient Safety: Making health care safer, launched in 2017, most adverse events are due to surgical procedures (27\%), followed by medication errors (18.3\%) and health-associated infections (12.2\%), which means that more than six million patients are likely to die during or after surgery, making the discussion on pediatric perioperative safety relevant ${ }^{(3)}$.

The association between death and adverse event in the national context was presented in a descriptive study between 2014 and 2016, recording a total of 63933 adverse events related to health care. Of these events, 417 (0.6\%) died. The study inferred that the highest incidence, that is, $89 \%$ of the total notifications of events, occurred in care with intense use of technologies and during the provision of care, diagnostic performance, evaluation and surgical intervention ${ }^{(5)}$.

It is estimated that, each year, four million pediatric surgical procedures are performed in the United States ${ }^{(6)}$, indicating the need for the perioperative nursing team to reconcile child care with the use of technologies, to promote safety and to instrumentalize the systematization of perioperative nursing care. The benefits of using technologies such as checklist are associated with decreased mortality and pediatric surgical complications ${ }^{(2)}$.

Therefore, the understanding of technologies in the Nursing area is a complex construct, which involves the search for innovations capable of transforming the context in which it is inserted ${ }^{(7-8)}$. The technologies, in Nietsche's conception, can be understood as processes realized from the apprehension and the application of a set of knowledge and assumptions that provide men to dominate processes and products and transform popular knowledge into scientific knowledge. In its conceptualization, specific technologies for Nursing are classified into: Administration Technologies, Conception Technologies, Conduct Technologies, Care Technologies,
Client Situation Interpretive Technologies, Communication Process Technologies and Education Technologies(7).

Offering safe care to pediatric patients, guided by international safety goals and specific technologies, enables improvements in perioperative care and aims at quality nursing care provided. This context consists of several technologies, which are constantly changing. The work process of the nursing team ensures their availability for safe pediatric care, due to the fact that children have anatomical and physiological differences, different stages of development and specific needs $s^{(9)}$.

Studies regarding the use of Nursing Technologies associated with safe perioperative pediatric nursing care are scarce. Thus, this study is relevant to the area of pediatric nursing, and specifically perioperative, since studies on the subject makes it possible to prevent and reduce adverse events. The guiding question of this study was: what is the perception of the nursing team regarding the use of technology for safe care in pediatric perioperative, through photographs? Thus, the objective of this study was to understand the perception of the nursing team regarding the use of technology for safe care in pediatric perioperative, through photographs.

\section{METHODOLOGY}

Qualitative approach study, descriptive and exploratory, aiming to understand the use of technologies for safe care in pediatric perioperative through the perception of nursing professionals, using semi-structured interviews and photographs. The study followed the Consolidated Criteria for Reporting Qualitative Research (COREQ) ${ }^{(10)}$, to ensure methodological rigor. Its theoretical reference was the Specific Nursing Technologies proposed by Nietsche. The philosophical proposal of the classification is divided into seven typologies, as already mentioned: Administration, Conception, Care, Education, Client Situation Interpretive, Conduct and Communication Process ${ }^{(7)}$.

Study conducted in a private hospital in southern Brazil, in the adult and pediatric perioperative unit, which includes pre-surgical, trans-operative and post-anesthetic recovery room. This service has three beds for the pre-surgical period, five operating rooms and a post-anesthetic recovery room with six beds, with a monthly demand of approximately 54 pediatric procedures. The nursing team is composed of four nurses and 20 nursing technicians.

It is worth mentioning that all nursing professionals in the sector were invited to participate in the study, however, following the criteria, six participants were excluded, three of them for being absent due to vacation or leave at the time of data collection, one for exercising the function in less than 
the established time and two of them for not accepting to participate in the study. Thus, the total number of participants was 18 nursing professionals.

The inclusion criteria were: being a nurse or nursing technician and performing their functions in the perioperative period at the time of data collection; presenting an admission period in the unit longer than three months, since this was considered the minimum time for the employee to adapt to the work unit; and having the skills and knowledge to handle the camera. Exclusion criteria: not completing the study interview.

Participants were identified by the letter " $\mathrm{N}$ ", for Nurse, followed by an ordinal number, and $\mathrm{T}$ for Nursing Technician - in this category, the letters $P$ for pre-surgical, $T$ for trans-operative and $R$ for post-anesthetic recovery were added, and an ordinal number corresponding to the order of the interview, preserving the identity of the interviewee.

Data collection occurred in two stages between June and August 2018, during the day and night period, with the first stage being performed during the work shift of the participants, with the authorization and release of the immediate Chief and, for the second stage, it was scheduled an interview with the participants at a more convenient time to them.

The first stage consisted of presenting the study to the professionals individually and, for those who agreed to participate, the Informed Consent Form and the consent to use the photographs and recording of the interview were delivered, as well as the digital cameras. The participant was invited to produce photos (at least 14 photos), recording facts, settings, situations and artifacts, in order to register the Nursing Technologies that are inserted in the perioperative period and that promote safe care for pediatric patients.

It is worth mentioning that it was requested that people and patients were not identified in the photos, according to the guidelines of the Research Ethics Committee, ensuring confidentiality and ethics.

After the end of this period, the camera was collected, an interview with the participant was scheduled and the photos were printed.

The second stage consisted of an individual interview, in a private room of the Institution, with an average duration of one hour, recorded in a digital recorder, after the participant's authorization. Therefore, we used a semi-structured instrument, divided into three topics: the first topic consisted of characterizing the participants; the second one in the conceptualization and classification of Nietsche's Specific Nursing Technologies (diagram) and the classification Likert Scale for the degree of relevance for pediatric patient safety; and, the third topic covered questions from the adapted Script "Image Watching".
Thus, in the second stage of data collection, the semi-structured instrument was applied and printed photos were delivered, instructing the participant to classify them in relation to Nietsche's Specific Nursing Technologies, exposed in a diagram (this diagram contained the title and the concept of each typology), and it was explained to the participants that they should read the concepts of each typology, and that the photos could be classified in more than one technology, and if there were doubts about the referential, the researcher could answer them. Subsequently, it was requested that, within each technology, the participants should reclassify the photos according to the degree of relevance to the safety of the pediatric patient, using the Likert scale (Totally Irrelevant; Irrelevant; Partially Relevant; Relevant; Totally Relevant). After that, the participant was asked to choose the most representative photograph for the safe perioperative pediatric patients within each typology, and to analyze it from the questions in the adapted script of "Image Watching"(12).

The "Image Watching" Script enables a more accurate reflection of the representativeness of the object in the captured photo ${ }^{(11)}$. Thus, the questions in this script were adapted and guided the interview on the photos: Describe the technology in the photo; Why did you choose this photo? Why did you classify it on this technology? What does the photo represent for safe care? Where is the technology in the photo? How is the technology used in the operating room represented? How does the technology in the photo assist in the safety of pediatric patients?

Data analysis was performed using the Thematic Content Analysis ${ }^{(11)}$, the participants' responses regarding the semi-structured instrument, that is, it involved the conceptualization and classification of the photos according to Nietsche's Specific Nursing Technologies and their reclassification using the Likert Scale for the degree of relevance to pediatric patient safety; and, the questions of the adapted Script "Image Watching"(12). Thus, in the first stage of the Thematic Content Analysis: listening to the speeches attentively, afterwards, there was the transcription and detailed reading of the meanings attributed.

In the second stage (exploration of the material), a deep reading and organization into categories that represented the analysis of the responses regarding the photographs and interviews was done. And, in the third stage, there was the appreciation, inference and interpretation of the results in new theoretical dimensions. It is worth mentioning that during the thematic analysis, a relationship was made between the recorded photos, the participants'responses and the theoretical reference of Specific Nursing Technologies proposed by Nietsche. 
Regarding ethical issues, this study was guided and respected the guidelines and regulatory standards of Resolution No. 466/2012, and it was approved on Brazil Platform, under the Certificate of Presentation for Ethical Appreciation (CAAE) No. 86292818400000121.

\section{RESULTS}

The study participants were: four nurses and 14 nursing technicians, most of them were women aged between 25 and 55 years old. Regarding the length of professional experience in Nursing, it was less than five years for most participants. As for working time at the Institution, one participant worked for more than 15 years and the other 17 participants, less than five years.

From the data analysis, the Nursing Technologies category used for the safety of pediatric patients in the perioperative emerged.

\section{Nursing Technologies used for the safety of pediatric patients in the perioperative period}

Participants recorded a total of 250 photos illustrating facts, settings, situations and artifacts they consider technologies used by nursing for safe pediatric care. Regarding the distribution of the classification table on the relevance for safe care in the pediatric perioperative, there is a highlight, that is, a greater number of photos classified as totally relevant (160), followed by the relevant ones (70) and less frequently, partially relevant (20). While the irrelevant and totally irrelevant variables did not obtain any classified photograph (Table 1).

When analyzing the relevance by technology typology, technologies with the greatest number of classified photos were: Care (103), Conception (58) and Conduct (43). In a lower frequency, the Administration (05) and Education (03) technologies (Chart 1).

Based on the classification of the photographs as to the choice of type of technology and the relevance for safe care, each participant was asked to choose, from the photographs taken by him/her, a photo of each typology that was most representative for patient safety, to be analyzed by the "Image Watching" adapted script.

In total, we obtained 74 photos, but it should be noted that there were typologies with less representation. Thus, there are typologies with a greater number of photographs, and some of them were classified into more than one typology (Figure 1 and Figure 2).

\begin{tabular}{|lccccc|c|}
\hline Specific Nursing Technologies & TR & R & PR & IR & TI & N \\
\hline Care & 68 & 30 & 5 & 0 & 0 & 103 \\
Conception & 35 & 17 & 6 & 0 & 0 & 58 \\
Conduct & 26 & 9 & 8 & 0 & 0 & 43 \\
Client Situations Interpretative & 14 & 7 & 0 & 0 & 0 & 21 \\
Communication processes & 11 & 5 & 1 & 0 & 0 & 17 \\
Administration & 4 & 1 & 0 & 0 & 0 & 5 \\
Education & 2 & 1 & 0 & 0 & 0 & 3 \\
\hline Total & 160 & 70 & 20 & - & - & 250 \\
\hline
\end{tabular}

Chart 1 - Classification of photos within Specific Nursing Technologies(6) according to the relevance for safe care in the pediatric perioperative. Florianopolis/SC, Brazil, 2019.

Source: Authors, 2019.

*TR-Totally Relevant; R- Relevant; PR- Partially Relevant; IR- Irrelevant;

TI- Totally Irrelevant. 


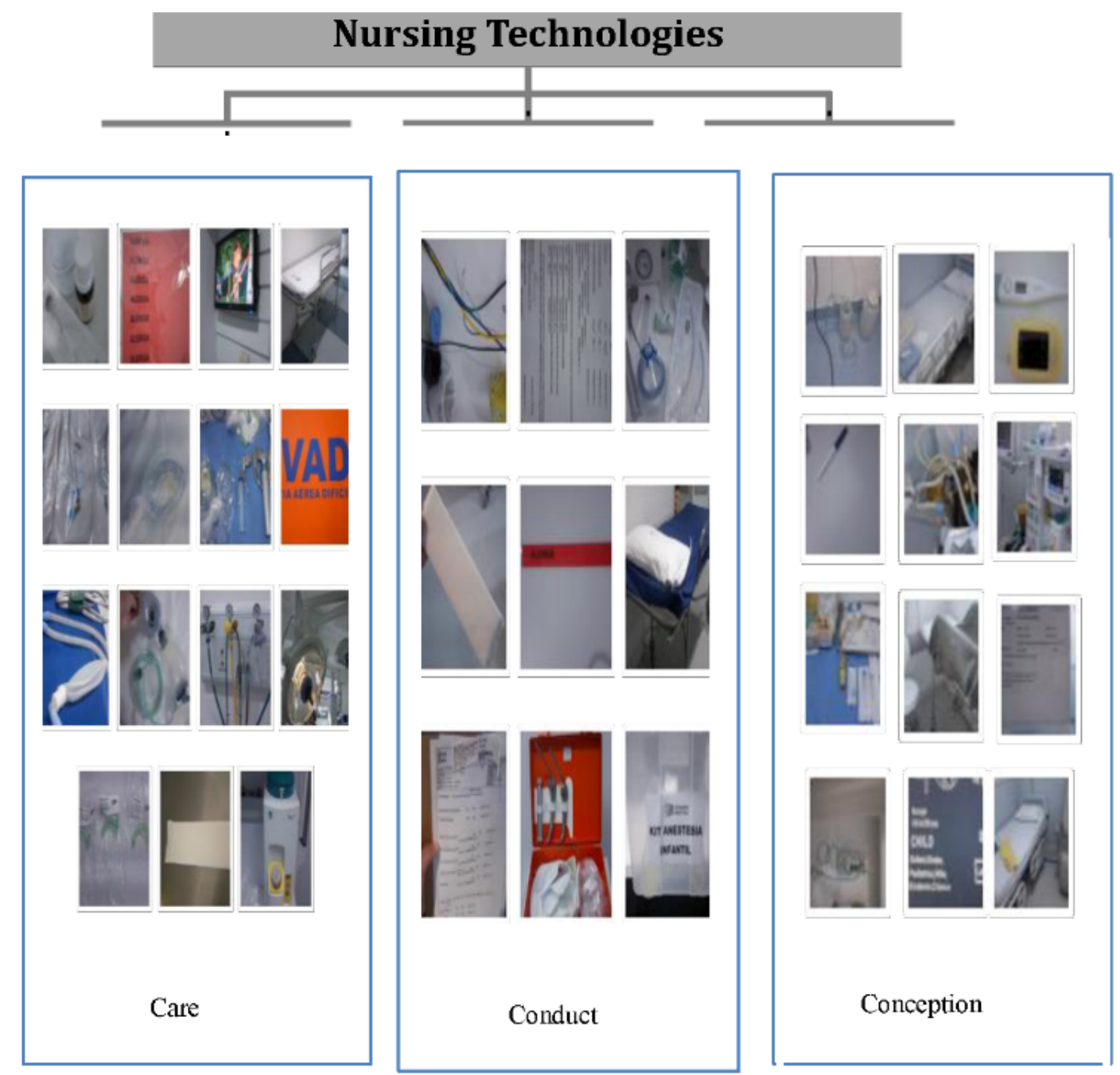

Figure 1 - Photos of the most representative technologies for the safe perioperative pediatric patients, distributed in the following typologies: Care, Conduct and Conception Source: Authors, 2019.

Figure 1 shows the representativeness of each technology captured in the photos, by participant, and, mainly, shows the choice of technologies that represent the profession's daily life in pediatric perioperative care.

The total number of photographs classified in the Care typology was 18, as referenced, and the photos expressed technologies such as Guedel cannula, aspirator, blades, respirator; difficult airway kit and splint to protect peripheral venous access (made by professionals to ensure the safe administration of anesthetic and post-surgery drugs); as well as photos that represent the preparation of the room and the technological devices were also chosen. For example, the participants represented the aspiration system assembled and tested in the photo in order to provide safe nursing care. It should be noted that this photo was chosen as representative for security by two participants: aspirator [...] really is a care technology! It is our responsibility regarding the patient, if it is not ready when I need to use it, it gets complicated. (N1).

In the Conception Technologies, a total of 15 photos were expressed, the participants exemplify the importance of marking the site of the procedure performed in the preoperatory with the parents, through the representation of a pen. And they also chose photos that represent the anesthesia carts conference; aspirator, pediatric peripheral vein puncture material and tray with anesthetic medications, wonder report (individual panel used for surgical planning and preparation, which contains information on the type of surgery, material, weight, height, allergy, surgical risk), oxygen mask mounted on the network of the post-anesthetic recovery room, infant sphygmomanometer. The participants 
also exemplified, from the photos, the beds prepared and adapted for the child, as well as the zeal to prepare the bed as a blanket in order to warm the child.

[...] as they are small, have lower body mass than an adult, and were under surgery for one, two hours, with air conditioning on all the time, it is important to make the bed very thick. Children lose temperature easily. (TR3).

The Conduct Technologies conceive the feasibility of nursing work, the excellence which they perform their work, and the seriousness and responsibility in the handling of technological devices, from planning to the execution of their practice, and a total of 13 photos were chosen to express the safety of the perioperative patient. The photographs in this typology reflect the work performed in the perioperative period: aspirator, prepared intubation material (pediatric orotracheal tube, mask, laryngoscope, guedel cannula); difficult airway kit and child anesthesia kit; splint to protect peripheral venous access; the allergy bracelet was expressed through the photograph twice, and the checklist for safe surgery three times.

I think that everyone thinks this checklist is important [...] it is a norm of the hospital to ensure patient safety. Here is the confirmation of the procedure that the patient will do, [...] also, the fasting here is the confirmation of laterality. (TP3).

Still, they illustrate the equipment used to transport the child, highlighting that it is not specific for the age group, demonstrating knowledge of the need for safe transportation, and recognizing that the act, when performed on an adult stretcher, does not fully ensure the child, allowing the occurrence of adverse event.

[...] I have never seen a pediatric stretcher in fact [...] if there was a pediatric stretcher, it would influence their safety [...] avoiding falls, due to the midazolam issue, it would guarantee their safety, it means safety. (TP2).

In addition to the technologies of Care, Conception and Conduct, the other typologies also had representativeness, but they were classified with a smaller number of photographs (Figure 2).

The Interpretive Technologies of Client Situations that were expressed by 13 photos were important because they are conceptualized as a means of helping the process of knowledge and understanding of the feelings of the child and family, as well as in communicating with them. Highlighting the playfulness that is represented by the toy and the shirt with a children's print, chosen by five participants, followed by photographs of the cardiovascular monitor, electronic surgical panel, pulse oximeter, wonder report, anesthesia cart.

[...] the toy is important for the children [...] bringing the toy is a way that the children have to be with something that is theirs [...] letting them take the toy makes them feel much safer. It helps because the toy belongs to the children, at home, certainly, they keep the toy with them all the time. (TP3).

The Communication Process typology, represented by nine photographs, even with the smallest number, described the children's world as representative for the safety of the pediatric patient, exemplifying the toy, the physical space without pediatric reference, the phone, the shirt, the surgical panel and the companion's chair.

He took the toy on that day [...] it made communication and care easier [...] the toy represents feeling more confident [...] it is their attachment and security to feel better. (TT3).

The Administration and Education technologies obtained a total of four and two photos, respectively, and of the total number of participants, four of them chose these typologies. The technologies expressed in photos for the Administration typology had as representativeness the surgical agenda, the shift, the surgical panel and the wonder report; and the photos selected for the Education typology found the companion's chair and the wonder report as technologies used in the management of pediatric care and in guaranteeing the child's safety in the perioperative period.

[...] we call it the "Wonder Report", it is exclusive to each patient, [...] / consider it an administration tool because, based on the wonder reports, we manage material, equipment, team [...] all the information comes out, every raw equipment and material I need inside the room [...]. In this wonderful report, there is a risk of APAE by the anesthetist, it signals a complex, syndromic patient [...] (N2).

The speeches together with the photographs demonstrated the need to use technological devices as artifacts for safe care, as well as for the proper reception of children in the perioperative. 


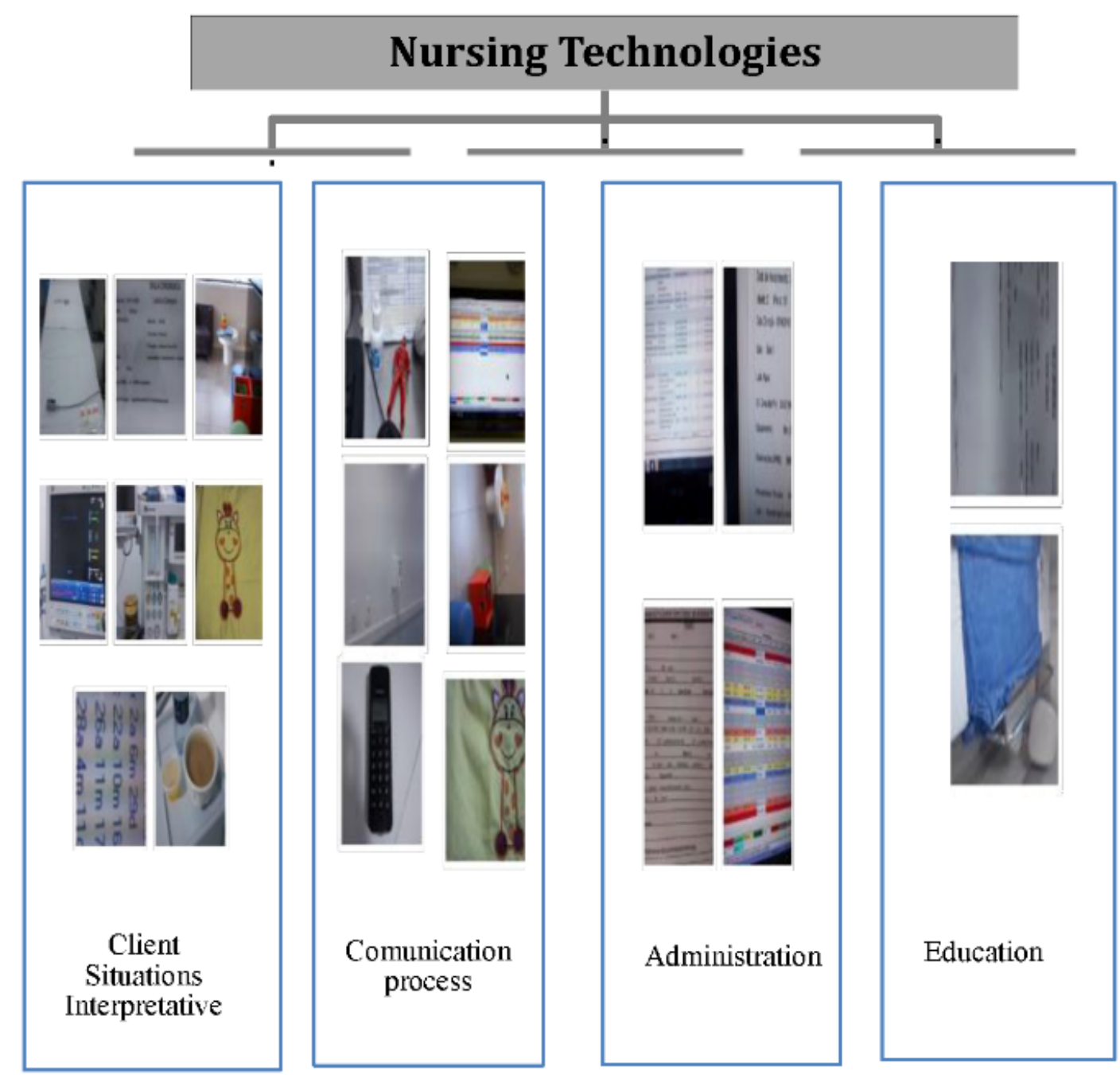

Figure 2 - Photos of representative technologies for the safety of pediatric patients in perioperative, distributed in the following typologies: Client Situations Interpretative, Communication Process, Administration and Education. Source: Authors, 2019.

\section{DISCUSSION}

As the number of pediatric surgeries increases in general hospitals, the need for complete and realistic assessments of available technological resources is vital in ensuring the safety of pediatric patients ${ }^{(13)}$. The findings of this study, as well as in an American study, provide Nursing the responsibility to transmit the importance of technologies in the optimization of safe pediatric care ${ }^{(14)}$.

The analysis of photos classified as representative for the safety of pediatric patients brought the typology of Care as the work developed by the team to prepare the ventilatory support materials. The importance of airway maintenance is evidenced when the participants represent the Care technologies in the photos of equipment and instruments used to provide safe ventilatory care to the child. Checking the availability of materials needed for anesthesia, such as those used to establish a patent airway, oxygenation, monitoring and medications, is one of the most critical concepts of pediatric perioperative and post-anesthetic ${ }^{(6,15)}$.

The continuity of perioperative care continues with the preparation and adaptation of the physical space for the care of the child, which, in line with Nietsche ${ }^{(7)}$, is a Conception technology because it is a unique work of Nursing based on scientificity. The proposal for the adequacy of devices for pediatric client care was in the speeches of the nursing team, as well as other considerations regarding the development of technologies consistent with the conception technology.

Specific nursing interventions during the post-anesthetic, such as the child's thermal control evidenced in the speeches 
and in the photos, corroborate the studies that indicate the importance and difficulty in regulating body temperature during the perioperative period, as it is a population with increased risk of heat loss due to thin skin, lack of subcutaneous fat and limited compensatory mechanisms $s^{(6,16)}$. Thus, photos of beds prepared to warm the child express the strategy that nursing seeks to reduce adverse events related to the thermal instability of the pediatric patient undergoing surgical procedures.

Ensuring the child safe nursing and multiprofessional care in perioperative is closely linked to ensuring the transmission of information relevant to the continuity of care in a safe manner, which is why they were identified by the participants as Conduct technologies. Studies confirm the importance of transferring information, such as allergies, administration of medications and doses, site of surgery, among care providers, for planning surgical care ${ }^{(14-15,17)}$.

Another technology exemplified by the photos and speeches as representative for the child's safety in perioperative was the toy, being classified into two categories, that is, Communication Process and Client Situation Interpretative technologies. Participants, in line with other studies, recorded the impact of hospitalization on children's imagination, even though the hospital is considered a place of healing and care, they expressed feelings of sadness and fear and that the presence of the toy brings the care team closer to the subject and assists in communication between both ${ }^{(16-17)}$.

The nursing team brought the need for immersion in the pediatric context, referencing to the aesthetic adequacy of the physical environment, with the use of paintings, drawings, children's characters, toys and televisions, in order to characterize it as a proper space for the treatment of children. Participants classified them as Communication technologies, as they facilitate the approach and dialogue with the child, supporting therapeutic listening ${ }^{(7,9)}$. In addition, care is also verified regarding the hospitalization process and the surgical procedure for both the child and the family. A recently published study infers that the partnership with people of primary reference in the post-anesthetic recovery room changes the child's safety and confidence experiences, improves safety levels and improves the communication process ${ }^{(8)}$.

Participants identified photos of technologies representative of pediatric safe care that show the infrastructure of the perioperative service, which differs for pediatric and adult surgery. The presence of trained professionals, physical and structural technologies, such as a pediatric stretcher and pediatric beds, are favorable resources for the safety of pediatric patients ${ }^{(18)}$.
The participants pointed out that the structure imposes limits on the care provided, consequently, it requires the nursing team efforts to use, adapt and create safe means necessary to assist the pediatric patient.

Still, in this context, a technology presented as relevant to safety was the "wonder report", chosen as a representative in two technologies: Administration and Education. This was considered as a representative technology for the safety of pediatric patients because it contains identification data, procedures and equipment used in surgery, allergy, risk scales and the child"s weight and height. Its use brings advantages such as the prevention of events associated with medication, since in pediatrics precision of the dosage calculations of medicines is necessary, and this calculation is based on the child's weight ${ }^{(18)}$.

The technologies are present in the care provided to each patient and their use by the team is directly related to ensuring the execution of the anesthetic-surgical process ${ }^{(19)}$. In contrast, the findings of this study showed the need for emancipatory empowerment of the class on the responsibility and importance of administration and education technologies in this process. The management of materials and the surgical unit, from the acquisition, conservation to the use of these by the nursing team, is essential for the unit to be prepared for routine care and eventual complications ${ }^{(20)}$.

\section{CONSIDERATIONS}

The classification of technologies represented by photos used for patient safety in the perioperative period was perceived by the nursing team as a relevant question in the provision of safe care, as well as in the identification of risk factors linked to structural, physical, inputs and materials aspects. Still, it was pointed out that they can be used to understand the children's world and imaginary.

Therefore, the study points out that the nursing technologies, in addition to enabling the reception of the child and family from the preoperatory to the discharge from the post-anesthetic recovery room, are still linked to technical procedures, assistance, systematization of care and the organization of perioperative nursing work. Thus, contributing to professional practice and nursing education.

As study limitations, it is considered that the interviews were not returned to the participants for reading and approval of the described content; it was developed in a single study setting; and the Institution does not exclusively serve the pediatric population. 


\section{REFERENCES}

1. Organização Mundial da Saúde (CH). Segundo desafio global para a segurança do paciente: cirurgias seguras salvam vidas. Rio de Janeiro (BR): Organização Pan-Americana da Saúde, Ministério da Saúde, Agência Nacional de Vigilância Sanitária; 2009 [cited 2017 abril 14] Available from: https://bvsms.saude.gov. br/bvs/publicacoes/seguranca_paciente_cirurgias_seguras_salvam_vidas. pdf

2. Almeida RE, Rodrigues MCS. Implementation of the surgical safety checklist for pediatric operations: compliance assessment. Rev Gaúcha Enferm. 2019;40(spe):e20180270. doi: https://doi.org/10.1590/1983-1447.2019.2018 0270

3. World Health Organization $(\mathrm{CH})$. Patient safety: making health care safer. Geneva: WHO; 2017 [cited 2017 Oct 24]. Available from: https://apps. who.int/iris/bitstream/handle/10665/255507/WHO-HIS-SDS-2017.11-eng. pdf? sequence $=1 \&$ is Allowed $=y$

4. Stockwell DC, Landrigan CP, Toomey SL, Loren SS, Jang J, Quinn JA, et al. Adverse events in hospitalized pediatric patients. Pediatrics. 2018;142(2):e20173360. doi: https://doi.org/10.1542/peds.2017-3360

5. Maia CS, Freitas DRC, Gallo LG, Araúio WN. Registry of adverse events related to health care that results in deaths in Brazil, 2014-2016. Epidemiol Serv Saúde. 2018;27(2):e2017320. doi: https://doi.org/10.5123/ s1679-49742018000200004

6. Derieg S. An overview of perioperative care for patients. AORN J. 2016;104 (1):4-10. doi: https://doi.org/10.1016/j.aorn.2016.05.001

7. Nietsche, E A. Tecnologia emancipatória: possibilidade ou impossibilidade para a práxis de enfermagem? [tese]. Florianópolis (SC): Universidade Federal de Santa Catarina; 1999.

8. Danielsson L, Lundström ML, Holmström IK, Kerstis B. Anaesthetizing children: from a nurse anaesthetist's perspective: a qualitative study. Nurs Open. 2018;5(3):393-9. doi: https://doi.org/10.1002/nop2.147

9. Gironés-Muriel A, Campos Segovia A, Alvargonzález Slater L, Fernández S. Hospital programs to treat childhood anxiety: review of evidence. Rev Elect Anestesiar. 2018 [cited 2018 Mar 31];10(6):4. Available from: http:// revistaanestesiar.org/index.php/rear/article/view/714/1148
10. Tong A, Sainsbury P, Craig J. Consolidated criteria for reporting qualitative research (COREQ): a 32-item checklist for interviews and focus groups. Int J Qual Health Care. 2007;19(6):349-57. doi: https://doi.org/10.1093/intahc/ mzm042

11. Minayo MCS. 0 desafio do conhecimento: pesquisa qualitativa em saúde. 14. ed. São Paulo: Hucitec; 2014.

12. Ott RW. Ensinando crítica nos museus. In: Barbosa AM, organizador. Arteeducação: leitura no subsolo. São Paulo: Cortez; 1997. E-book.

13. Arca MJ, Goldin AB, Oldham KT. Optimization of care for the pediatric surgical patient: why now? Semin Pediatr Surg. 2015;24(6):311-4. doi: https://doi. org/10.1053/j.sempedsurg.2015.08.010

14. Johnson Q, Mcvey J. Enhancing pediatric perioperative patient safety. AORN J. 2017;106(5):434-42. doi: https://doi.org/10.1016/j.aorn.2017.09.007

15. Martins LA, Silveira SPX, Avila IMFT, Moraes JAS, Santos DSS, Whitaker COM, et al. Thermoregulation protocol implementation for newborns in surgical procedures. Rev Gaúcha Enferm. 2019;40(spe):e20180218. doi: https://doi. org/10.1590/1983-1447.2019.20180218

16. Silva MF, Anders JC, Rocha PK, Souza AIJ, Burciaga VB. Communication in nursing shift handover: pediatric patient safety. Texto Contexto Enferm. 2016;25(3):e3600015. doi: https://doi.org/10.1590/0104-070720160036 00015

17. Ribeiro JP, Gomes GC, Oliveira BB, Klemtz FV, Soares PP, Silva PA. Comfortableness of pediatric unit: perspective of users, nursing professionals and nursing managers. Rev Enferm Centro-0este Mineiro. 2018;8:e2055. doi: https://doi. org/10.19175/recom.v8i0.2055

18. Souza TLV, Mota RO, Brito EAWS, Farias LMVC, Matias EO, Lima FET. Patient safety in the administration of intramuscular medication in pediatrics: assessment of the nursing practice. Rev Gaúcha Enferm. 2018;39:e2017-0002. doi: https:// doi.org/10.1590/1983-1447.2018.2017-0002

19. Salbego C, Dornelles CS, Greco PBT, Pradebon VM, Alberti F. The meaning of care for operating room nursing. Rev Rene. 2016;16(1):46-53. doi: https://doi. org/10.15253/2175-6783.2015000100007

20. Jost MT, Viegas K, Caregnato RCA. Systematization of perioperatory nursing assistance in patient safety: an integrative review. Rev SOBECC. 2018;23(4):21825. doi: https://doi.org/10.5327/z1414-4425201800040009

\section{- Corresponding author:}

Sheila Cristina da Silva Ferraz

Email: shecrisenf@gmail.com

\section{Associate editor:}

Wiliam Wegner

Received: 08.02.2019

Approved: 02.12 .2020

\section{Editor-in-chief:}

Maria da Graça Oliveira Crossetti 